\title{
Identification of novel drug candidate against Mycobacterium Tuberculosis InhA protein through Computer aided drug discovery
}

\author{
Nisha T. Nair ${ }^{1}$, Shefin Nisthar ${ }^{2}$, Bindu A. Sunil kumar ${ }^{3,4}$ \\ ${ }^{1}$ Department of Biotechnology, Malankara Catholic College, Mariagiri. \\ ${ }^{2}$ JRF saraswathy thangavelu extension center. Jawaharlal Nehru tropical botanic garden, Trivandrum. \\ ${ }^{3}$ Centre for Food for Health Science, Lund University, Lund, Sweden. \\ ${ }^{4}$ Department of Computational Biology and Bioinformatics, University of Kerala, INDIA.
}

\begin{abstract}
Tuberculosis is a common and often deadly infectious disease caused by Mycobacteria. WHO estimates that around eight million people are suffering from tuberculosis every year. The Administration of antibiotics fails due to the multi-drug resistant capability of Mycobacterium. Traditional methods require time and huge investment. Therefore, it is essential to provide an alternative strategy to treat tuberculosis disease. The present study conducted molecular docking against InhA protein, which is a potential target of tuberculosis disease. After docking with 1200 ligand molecule, 30 hits were selected based on the GOLD score. Finally, five potential hits were identified after redocking. The hydrogen bonding pattern, Lipinski's rule, and drug likeliness were also checked for their potentiality as suitable drug candidates. We believe that our study will facilitate the selection of InhA as a potential target and selected hits as successful drug candidates for tuberculosis diseases.
\end{abstract}

Key words: Active site docking, Hydrogen bonding, Latent infection, Ligand, Pathway, Resistant, Score, Selection, Target.

\section{INTRODUCTION}

Tuberculosis (TB) is one of the firstborn diseases among humankind caused by Mycobacterium tuberculosis. TB is presently becoming a potential threat to the global health scenario with 8-9 million people being reported every year with new active disease. ${ }^{1-3}$ The bacterium causing tuberculosis is Mycobacterium tuberculosis (MTB), a rod shaped bacteria that can thrive only in human beings. TB begins when the Mycobacteria reach the pulmonary alveoli, where they invade and replicate within the endosomes of alveolar macrophages. ${ }^{4}$ About $90 \%$ of those infected with MTB have asymptomatic, latent TB infection (LTBI). LTBI is a state where a person is infected with $M T B$ but patient does not have active TB. ${ }^{5,6}$ Active TB is contagious whereas LTBI is not. Therefore, it is not possible to get TB from patients with latent tuberculosis infection.

The antibiotics such as Isoniazid and Rifampicin are the two best anti-TB drugs, ${ }^{7}$ which are considered as the first-line drugs and are the first medicines used to treat all persons with TB disease. Extensively drug-resistant TB (XDR TB) is relatively a rare type of $\mathrm{TB}^{8}$ which is resistant to first-line drugs (Isoniazid and Rifampicin), plus any fluoroquinolone and at least one of three injectable second-line drugs (such as amikacin, kanamycin, or capreomycin). ${ }^{9}$ Multi-drug resistant tuberculosis (MDR-TB) is resistant to Rifampicin and Isoniazid (first line TB drugs). In 2010, the World Health Organization estimated that more than 650,000 people suffers from MDR TB. ${ }^{10}$ People with
Submission Date : 01-04-2016 Revision Date : :31-08-2016 Accepted Date : 20-09-2016

DOI: 10.5530/ijper.50.4.9 Correspondence: Bindu A Sunil kumar, Centre for Food for Health Science, Lund University, Sweden, Phone No. 046 2228323,

E-mail: bindu.sunilkumar@ food-health-science.lu.se

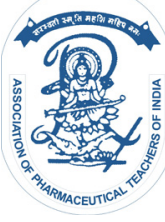

www.ijper.org 
MDR TB may need to take several antibiotics every day for up to two years. But even with this treatment, out of 6 patients with MDR TB will die, which is the same rate that is seen in people with TB who are not treated. ${ }^{11,12}$ Bacillus Calmette-Guerin (BCG) is the only vaccine available for prevention of TB in humans ${ }^{13,14}$ and is not that efficient to treat MDRTB. In addition, the techniques such as plating, microplate Alamar blue assay, BACTEC 460 etc. for identifying inhibitors of MTB are very expensive, tedious, and time consuming. ${ }^{15,16}$ Therefore, an immediate need for a new tuberculosis drug is essential to improve the current treatment by shortening the total duration of treatment and also to improve the treatment of MDR-TB and latent tuberculosis infection (LTBI). ${ }^{5}$

Recently IN SILICO methods are used to identify potential drugs for various diseases. It has developed as a cost effective and rapid tool for the discovery of novel therapeutic agents. It includes the identification of the target protein, which is responsible for the development of the disease under study. ${ }^{17,18}$ Such targets are bio-molecules, which in most cases are proteins such as receptors, enzymes, and ion channels. In this present study, inhibition of InhA, one of the main protein for mycolic acid production and cell wall synthesis of MTB(19) was conducted through molecular docking. A number of 1,200 small molecules virtually screened against InhA active site using GOLD (Genetic Optimization for Ligand Docking) software that uses Genetic Algorithm (GA). The total cell wall synthesis of mycobacterium can be ended through inhibition of InhA. In addition to redocking, H-bonding investigation, Lipinski's rule evaluation, and drug likeliness tests were also performed.

\section{MATERIALS AND METHODS}

\section{Identification and preparation of Target protein}

By studying the biochemical pathway of MTB through KEGG database, we found that InhA is involved in the synthesis of mycolic acids. InhA, which represents 2-trans-enoyl-acyl carrier protein reductase, is the target for the front-line anti tuberculosis drug" isoniazid". We retrieved the X-ray crystallographic structure of InhA target protein complexed with NAD from RCSB protein data bank. RCSB PDB (Research collaborator for structural Bio informatics) database is a repository for three-dimensional structures of protein and nucleic acids (http://www.rcsb.org). The active site of InhA protein was positioned within $3.5 \mathrm{~A}^{0}$ vicinity of ligand molecule using SWISS-PDB viewer software. ${ }^{17}$ The active site was prepared by ionizing key amino acid side chains by removing water molecules, adding, and optimizing hydrogen atoms into the protein through Argus Lab software (Argus lab 4.0.1). All the atoms that constituted the active site were listed and saved in a notepad.

\section{Validation of Target protein}

The downloaded structure was validated using Pro Check (Pro Check 2.3)(20). Ramachandran plot demonstrated the relationship between the phi and psi angles of InhA protein structure and the position of amino acids (aa).

\section{Ligand Input File Preparation and Optimization}

The ligand input structure of 1200 biologically annotated small molecules were retrieved ${ }^{21}$ from Meta Database Ligand (http://Ligand.Info). These molecules were visualized through SWISS PDB viewer and saved in SDF format for virtual high throughput screening. ${ }^{22}$

\section{Docking}

Docking refers to the ability to position a ligand into the active site of a protein. After preparation of target protein using SWISS PDB viewer and ligand file preparation, docking was performed using GOLD 5.0 (Genetic Optimization for Ligand Docking) program. ${ }^{23}$ By using the docking wizard of GOLD program, preparation of protein was performed by both binding pocket information and ligand library preparation. Hydrogen bond contacts, lipophilic interactions and non-bonded contacts were calculated using LIGPLOT 4.5.3. ${ }^{24}$ Hydrogen bonding pattern analysis was performed using SILVER, a post processing docking search algorithm.

\section{Re-docking}

Redocking helps to eliminate the false positive and negative rates caused by methodological errors. The first 30 molecules with high Gold Fitness Score obtained from docking studies have been used for redocking. Following redocking, strict visualization was performed using Pymol Software. Although GOLD offers a number of scoring functions like Gold Score, Chem Score and ASP (Astex Statistical Potential), Gold Fitness Score is more original and the default scoring function is ideal. ${ }^{25}$

\section{Hydrogen bonding investigation}

The PDB file of the re docked compounds for the hydrogen bonding analysis has been submitted to PDB sum server. ${ }^{26}$ This can be done via Generate option in EMBL-EBI website ${ }^{27}$ in which our mail address should also be provided. Once the run is over, the results will be sending to our mail. The result will highlight on the hydrogen bond details along with complete structural analysis. 


\section{Lipinski's Rule Filtering and Drug Likeliness Test}

The Lipinski's rule is essential for the PDB format of the compounds identified through docking and redocking process, to execute the filtering course. ${ }^{28}$ The $3 \mathrm{D}$ structures saved in PDB format has submitted to the drugfiltering tool at http://www,scfbio-iitd.res.in/utility/ LipinskiFilters.jsp.

\section{ADMET (Absorption, Distribution, Metabolism, Excretion, and toxicity) Test}

To select drug-like molecule, DruLiTo software was used to screen the selected five molecules based on filters namely Lipinski's rule, BBB rule, CMC-50 like rule, weighted and un-weighted Quantitative Estimate of Drug-likeness. DruLiTo is an open source virtual druglikeness tool, which can be freely downloaded from the internet. ${ }^{29-31}$ The selected compounds in SDF format was given to the DruLiTo software interface and proceeded to calculate the properties.

\section{RESULTS}

Molecular Docking continues to hold a great promise in computer aided drug designing which helps to screen small molecules by orientation and scoring them in the binding site of the protein. In this IN SILICO study, screening of 1200 molecules against target protein has resulted in five potential drug molecules that were validated with different bioinformatics tools.

\section{Identification of target protein through text mining}

InhA protein has been recognized through literature reviews using a wide variety of academic databases and search engines available online such as Drug Bank, Super Target, and STITCH. InhA (enoyl acyl carrier protein reductase) from $M$. tuberculosis is one of the most important enzymes involved in the type 11 fatty acid biosynthesis pathway. ${ }^{32-34}$ Mycobacterium tuberculosis involves type one fatty acid synthase (FAS1) and type two fatty acid synthase (FAS11) which functions together in the production of mycolic acids. These mycolic acids are long chain fatty acids (C54 to C64), that are necessary in cell wall formation of $M$. tuberculosis. FAS1 synthesizes C16-18 and C24-26 fatty acids which results in chain extension, forming long-chain meromycolic acids. ${ }^{21}$ The final reaction in FAS11 involves InhA reducing 2-transenoyl-ACP with chain lengths over twelve carbons in a NADP dependent manner. ${ }^{35-37}$ Therefore, inhibition of InhA proteins results in the inhibition of mycolic acid production and results in cell wall lysis. Thus, InhA is a potential drug candidate against the infection caused by Mycobacterium tuberculosis. InhA protein (PDB ID: 2H9I) complexed with NAD was downloaded from
PDB data bank displayed in Figure 1. The structure was displayed using Swiss PDB viewer and active site was prepared with the help of Argus Lab software. ${ }^{38}$

\section{Validation of target protein}

The distribution of backbone dihedral angles of InhA was judged with Pro Check programme to see the quality of the protein. The Phi and Psi scatter plot is shown in Figure 2. Ramachandran $Z$ score was validated. The Validation of InhA protein using Ramachandran plot analysis shows percentage of residues in the most favored regions, additionally allowed regions, generously allowed regions, disallowed regions, and G-Score. The Phi and Psi angles showed a considerable conformational freedom in the two torsion angles, but with a number of close restrictions. A comparison of $\mathrm{Z}$ score with Procheck was done. It is clear that although there is a strong correlation between the score, pairs of structure in which percentage of their residues are in the most favoured areas as defined by Pro-check.

\section{Preparation of active site}

Active site of InhA was prepared using PDB sum server in which the active site residues of the natural ligand were selected (Figure 3). Almost 7 amino acids residues such as glycine 14 , serine 20 , isoleucine 21 , valine 65 , isoleucine 95, lysine 165, isoleucine 194 located using PDB sum server were extended over at $3.5 \mathrm{~A}^{0}$ vicinity of the ligand molecule and viewed through the control panel of SWISS PDB, a viewer Standalone software application.

\section{Ligand structure retrieval}

From a database named Meta Database Ligand (http:// Ligand.Info), ligand input structure of 1200 biologically annotated small molecules were retrieved. These molecules were visualized using SWISS PDB viewer and

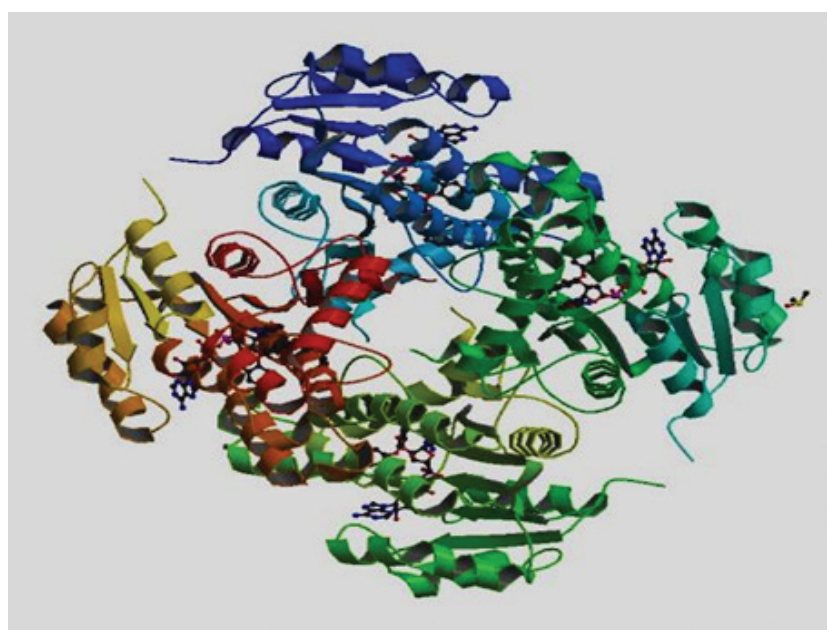

Figure 1: InhA protein with natural ligand NAD (2H9l) 


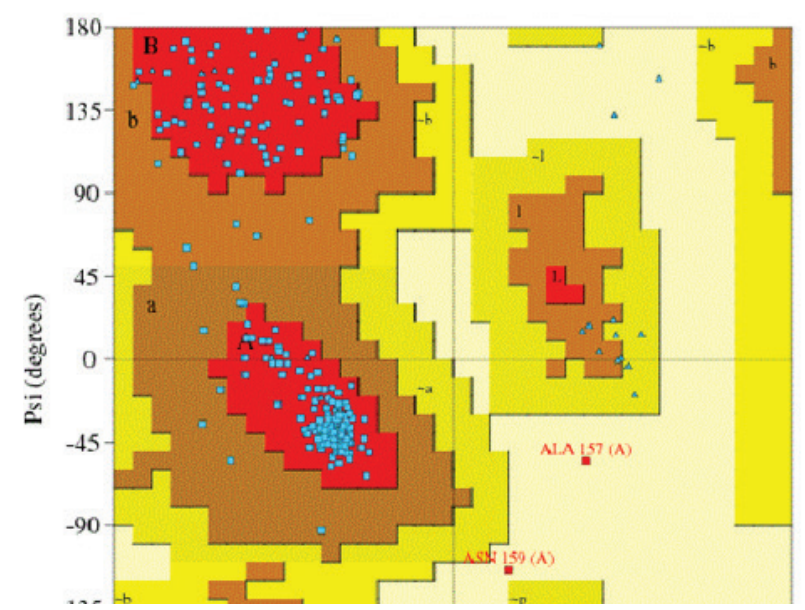

Figure 2: Ramachandran plot of InhA protein generated using ProCheck 2.3 to find stable conformations. The red, brown, yellow regions represent the favored, allowed and generously allowed regions respectively, where the circles and squares represent amino acid of protein.

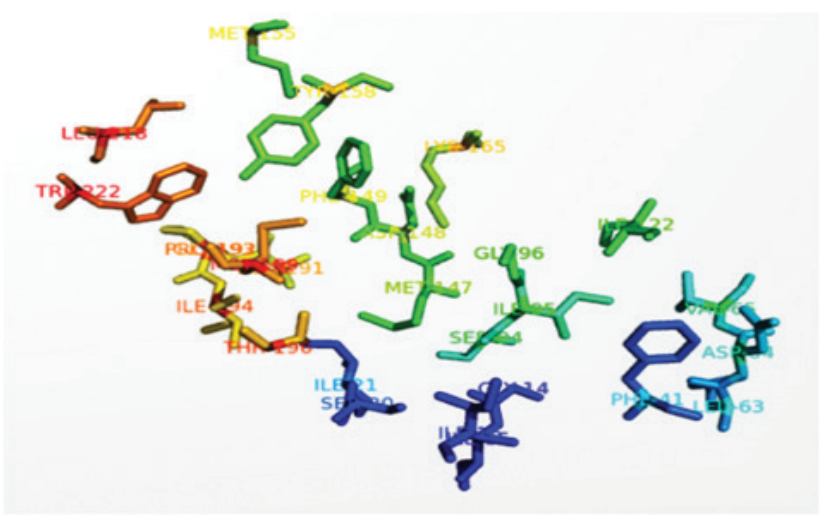

Figure 3: The active site of InhA target protein with amino acid residues such as glycine 14 , serine 20 , isoleucine 21 , valine 65 , isoleucine 95 , lysine 165 , isoleucine 194 located using PDB sum server.

then saved in SDF format for virtual high throughput screening.

\section{Initial screening using GOLD software}

Docking of InhA target protein was conducted using GOLD 5.0 software. Initially, the target protein was docked with about 1200 ligand compounds. Of the compounds docked, the first top 30 compounds were selected based on GOLD score, which ranges from 90.42 to 83.18 and is shown in Table 1 .

\section{Redocking}

As GOLD offers a variety of scoring functions like Gold score, ChemScore and ASP (Astex Statistical Potential), but Gold Fitness Score being the original and default scoring function is preferred. It also takes into account of factors like H-bonding energy, van der Waals energy,

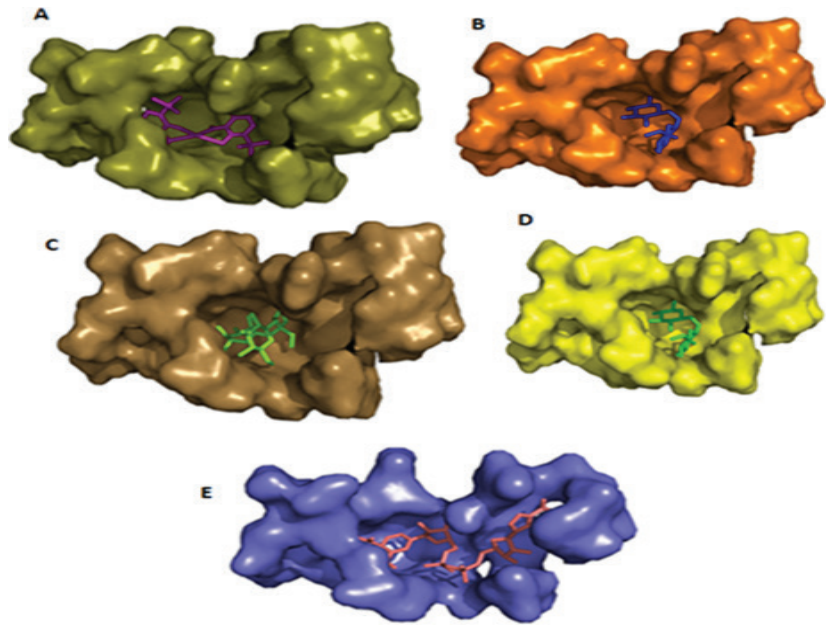

Figure 4: Structure of 5 docked complexes with InhA target protein.

InhA active site with 3-0-hexopyranosylhex-2-ulofuranosyl hexopyranoside with Gold Score 90.42

InhA active site with 9,10,16-trihydroxyhexadecanoic acid with Gold Score 88.35

A. InhA active site with 4-(1-pyrrolidinyl)butyl2-cyclopentylpentanoate2-hydroxy-1,2,3propanetricarboxylate with Gold Score 86.88

B. InhA active site with 2-(1-pyrrolidinyl)propyl2-cyclopentylpentanoate2-hydroxy-1,2,3-propanetricarboxylate with Gold Score 85.95

C. InhA active site with complexon V with Gold Score 83.18

metal interaction, and ligand torsion strain. The fitness score is the negative of the sum of the component energy items so that the larger score is the best. From the 30 best hits, redocking has performed to eliminate any false positives. Redocking was performed individually for their GOLD score and CHEM score. Five best leads with high GOLD fitness score was retrieved which is shown in Table 2 and the structure of the docked complex is shown in Figure 4. The 3D structures of the five compounds identified were generated using Corina interface with SMILES format of the ligands. ${ }^{39}$ Corina is a fast and powerful 3D structure generator for small and medium sized, mostly drug-like molecules. Its comprehensiveness, speed, and robustness enable the Corina to convert large chemical datasets or databases.

\section{Lipinski's rule filtering and Drug likeliness test}

Lipinski's rule states that poor absorption is anticipated, if the molecular weight is greater than 500; $\log \mathrm{P}$ greater than 5, Hydrogen bond donors greater than 5 and Hydrogen Bond acceptors greater than 10. ADMET test serves to analyze the disposition of a pharmaceutical compound within an organism. As shown in Table 2 as shown in Table 3, the selected 5 targets has satisfied Lipinski's Alert index values which indicate that the selected five targets are good candidates to be a drug. However, the behaviour and kinetics of drug molecule 
Table 1: The selected 30 lead molecules identified by virtual screening with corresponding GOLD (Genetic Optimization of Ligand Docking) Score

\begin{tabular}{|c|c|c|}
\hline $\begin{array}{l}\text { Sr. } \\
\text { no }\end{array}$ & IUPAC Names of Hit Molecules & GOLD score \\
\hline 1. & $\begin{array}{l}\text { 3-((4-0-(4-0-(3-0-acetyl-2,6-dideoxy-4-0-hexopyranosylhexopyranosyl)-2,6-dideoxyhexopyranosyl)-2,6- } \\
\text { dideoxyhexopyranosyl)oxy)-12,14-dihydroxycard-20(22)-enolide. }\end{array}$ & 99.69 \\
\hline 2. & $\begin{array}{l}\text { 3-((2,6-dideoxy-4-0-(2,6-dideoxy-4-0-(2,6-dideoxyhexopyranosyl)hexopyranosyl)hexopyranosyl)oxy)-14- } \\
\text { hydroxycard-20(22)-enolide. }\end{array}$ & 97.84 \\
\hline 3. & No name. & 96.75 \\
\hline 4. & $\begin{array}{l}\text { 2-((4-ethyl(3-sulfobenzyl)amino)phenyl)4-(ethyl(3-sulfobenzyl)-lambda 5 -azanylidene)-2,5-cyclohexadien } \\
\text { 1ylidene)methyl)benezenesulfonic acid. }\end{array}$ & 94.81 \\
\hline 5. & Hex-2-ulofuranosyl 6-0-hexopyranosylhexopyranoside & 94.66 \\
\hline 6. & $\begin{array}{l}\text { 3-((ethyl-4-((4-(ethyl(3-sulfobenzyl)-lambda 5 -azanylidene)-2,5-cyclohexadien-1-ylidene)(phenyl)methyl) } \\
\text { anilino)methyl)benzenesulfonic acid. }\end{array}$ & 93.45 \\
\hline 7. & 3-0-hexopyranosylhex-2-ulofuranosyl hexopyranoside. & 92.11 \\
\hline 8. & 3,7,12-trihydroxycholan-24-oic acid. & 91.81 \\
\hline 9. & 4-amino-N-(3,12-dihydroxy-24-oxocholan-24-yl)benzenesulfonamide. & 91.39 \\
\hline 10. & 4-(1-pyrrolidinyl)butyl2-cyclopentylpentanoate2-hydroxy-1,2,3-propanetricarboxylate. & 91.30 \\
\hline 11. & No name & 90.17 \\
\hline 12. & 3-0-hexopyranosylhex-2-ulose. & 89.87 \\
\hline 13. & 9,10,16-trihydroxyhexadecanoic acid. & 89.71 \\
\hline 14. & 2-methyl-5-((5-(4-methyl-3-sulfoanilino)-9-10-dioxo-9,10-dihydro-1-anthracenyl)amino)benzenesulfonic acid. & 89.63 \\
\hline 15. & No name & 89.52 \\
\hline 16. & $\begin{array}{l}\text { Phosphoric acid compound with } \mathrm{N} \sim 1 \sim, \mathrm{N} \sim 1 \sim \text { diethyl-N 4 -(1,2,3,4-tetrahydro-9-acridinyl)-1,4- } \\
\text { pentanediamine(1:1). }\end{array}$ & 89.36 \\
\hline 17. & $\begin{array}{l}\text { Phosphoric acid compound with N 1 -(7-chloro-1,2,3,4-tetrahydro-9-acridinyl-N 3 , N 3 -dipentyl-1,3- } \\
\text { propanediamine(1:1). }\end{array}$ & 89.27 \\
\hline 18. & $\begin{array}{l}\text { Phosphoric acid compound with N 1 -(7-CHLORO-1,2,3,4-tetrahydro-9-acridinyl)-N 3 , N 3 -diisopentyl- } \\
\text { 1,3-propanediamine(1:1). }\end{array}$ & 88.96 \\
\hline 19. & No Name & 88.56 \\
\hline 20. & 1-deoxy-1-(7,8-dimethyl-2,4-dioxo-3,4-dihydrobenzopteridin-10(2H)-yl)hexitol. & 88.19 \\
\hline 21. & $\begin{array}{l}\text { 3-((4-((2-chlorophenyl)(4-(ethyl(3-sulfobenzyl)-lambda 5 -azanylidene)-2,5-cyclohexadien-1-ylidene) } \\
\text { methyl(ethyl)anilino)methyl)benzenesulfonic acid. }\end{array}$ & 88.01 \\
\hline 22. & $\begin{array}{l}\text { 3-((4-((2-chlorophenyl)(4-(ethyl(3-sulfobenzyl)-lambda 5 -azanylidene)-2,5-cyclohexadien-1-ylidene) } \\
\text { methyl(ethyl)anilino)methyl)benzenesulfonic acid. }\end{array}$ & 87.95 \\
\hline 23. & Phenyl 4-0-hexopyranosyl-1-thiohexopyranoside & 87.36 \\
\hline 24. & Hexopyranosylhexopyranoside. & 87.30 \\
\hline 25. & 3-(1-pyrrolidinyl)propyl 2-cyclohexen-1-yl(2-cyclopenten-1-yl)acetate2-hydroxy-1,2,3-propanetricarboxylate. & 86.89 \\
\hline 26. & $\begin{array}{l}\text { Phosphoric acid compound with } \mathrm{N} \sim 1 \sim, \mathrm{N} \sim 1 \sim-\text { diisopentyl-N 3 -(1,2,3,4-tetrahydro-9-acridinyl)-1,3- } \\
\text { propanediamine(1:1). }\end{array}$ & 86.67 \\
\hline 27. & 4-0-hexopyranosylhexopyranose. & 86.36 \\
\hline 28. & No name. & 85.82 \\
\hline 29. & 2-(1-pyrrolidinyl)propyl2-cyclopentylpentanoate2-hydroxy-1,2,3-propanetricarboxylate. & 85.70 \\
\hline 30. & $\begin{array}{l}\text { 3-((ethyl-4-((4-(ethyl(3-sulfobenzyl)-lambda 5 -azanylidene)-2,5-cyclohexadien-1-ylidene)(phenyl)methyl) } \\
\text { anilino)methyl)benzenesulfonic acid. }\end{array}$ & 85.64. \\
\hline
\end{tabular}




\section{Table 2: Selected 5 lead compounds with IUPAC name with GOLD Score after Redocking}

\begin{tabular}{|c|c|c|c|}
\hline Hits & IUPAC name Molecular Formula & \multicolumn{2}{c|}{ GOLD Score } \\
\hline 1 & 3-O-hexopyranosylhex-2-ulofuranosyl hexopyranoside. & 90.42 \\
\hline 2. & $9,10,16-$ trihydroxyhexadecanoic acid. & $\mathrm{C} 13 \mathrm{H} 32 \mathrm{O} 16$ & 88.35 \\
\hline 3. & $4-(1-$-pyrrolidinyl) butyl2-cyclopentylpentanoate2-hydroxy- \\
$1,2,3$ propanetricarboxylate. & $\mathrm{C} 16 \mathrm{H} 32 \mathrm{O} 3$ & 86.88 \\
\hline 4. & $2-(1-$ pyrrolidinyl)propyl2-cyclopentylpentanoate2-hydroxy-1,2,3- \\
propanetricarboxylate. & C18H3402 & 85.95 \\
\hline 5. & No IUPAC name available. & $\mathrm{C} 20 \mathrm{H} 10 \mathrm{CuN} 2 \mathrm{O} 16 \mathrm{~S} 4$ & 83.18 \\
\hline
\end{tabular}

\begin{tabular}{|c|c|c|c|c|c|}
\hline Hits & IUPAC name & Mol. Wt & $\begin{array}{l}\text { H Bond } \\
\text { Acceptors }\end{array}$ & $\begin{array}{l}\text { H Bond } \\
\text { donors }\end{array}$ & Log P \\
\hline 1. & 3-O-hexopyranosylhex-2-ulofuranosyl hexopyranoside & 505 & 10 & 3 & -14.743 \\
\hline 2. & 9,10,16-trihydroxyhexadecanoic acid & 304 & 4 & 1 & -0.630 \\
\hline 3. & $\begin{array}{l}\text { 4-(1-pyrrolidinyl)butyl2-cyclopentylpentanoate2-hydroxy- } \\
\text { 1,2,3propanetricarboxylate }\end{array}$ & 487 & 6 & 4 & -1.364 \\
\hline 4. & $\begin{array}{l}\text { 2-(1-pyrrolidinyl)propyl2-cyclopentylpentanoate2-hydroxy-1,2,3- } \\
\text { propanetricarboxylate. }\end{array}$ & 473 & 7 & 6 & -1.754 \\
\hline 5. & Not Available & 464 & 6 & 2 & -5.658 \\
\hline
\end{tabular}

$\mathrm{H}$ bond- Hydrogen bond

depends on these criteria and needs to be evaluated further to detect its pharmacological activity as a drug.

\section{ADMET (Absorption, Distribution, Metabolism, Excretion, and Toxicology)}

The 3D structures of the selected five compounds were saved in PDB format and DruLiTo software was used to screen these selected compounds. ADMET properties are essential to identify the aggregate value to suitable candidates for drug development system. The five lead molecules exhibited efficient banding site, showed ideal $\mathrm{p} \mathrm{IC}_{50}(\sim 7.0)$ values and passed the rule of five. No experimental results were reported in the paper. However, these approaches helped us to identify the potency to use as effective drug candidates for future. Four out of 5 molecules are available in ChEMBL database. ${ }^{40}$

\section{DISCUSSION}

Tuberculosis (TB) is a potentially serious infectious disease. Several strategies have been employed for the development of new therapeutic agents against the drug resistant strains of Mycobacterium. Drug-resistant TB or DR-TB is used to describe those strains of TB which show resistance to one or more of the common first line drugs. Rifampicin and isoniazid are the firstline antibiotic agents used for prevention and treatment of tuberculosis. Both targets enoyl reductase (InhA) enzyme in fatty acid biosynthesis pathway of the Mycobacterium. Multidrug-resistant TB or MDR-TB is the condition in which the strains are resistant to rifampicin and isoniazid. Thus forceful efforts are needed for developing new anti-tubercular drugs to battle bacteria that are resistant to current therapeutic first line antibiotics and vaccines. Isoniazid (INH) is the corner stone for the prevention and treatment of $\mathrm{TB}$, both latent and active tuberculosis. It has been found that its administration can rapidly block bacterial spread and improves patient's conditions after a few weeks of treatment and has been administered to about 40 million people, thus saving millions of life. However, patients with MDR-TB that are resistant to first line antibiotics including Isoniazid has also shown resistance to second line-drugs such as fluoroquinolones. This condition is termed as extensively drug-resistant TB or XDR-TB. Poly-drug resistant TB is another category that are resistant to more than one of the first line antibiotics. However, patients infected with Mycobacterium show combinations of these different categories of resistance required combination of different medications to cure them.

There were several practical difficulties to treat or to identify suitable drugs identified during the literature survey for the present study. Detecting drug resistance is one of the main problem to treat TB. In addition, for each individual patient, there will be different pattern of 
resistance. Relative ineffectiveness against the pathogen, lengthy treatment, side effects after several treatment which requires additional medical managements are the other problems identified. Even though best treatment is available, some drug-resistant patient will go on to develop yet further resistance to their drugs. Also, the financial cost of treating drug-resistant TB is very high compared to treating a patient with drug-susceptible TB. These factors explain the practical difficulties to treat $\mathrm{TB}^{41}$

Taking into account of the long lapse of nearly 40 years for a new drug against TB to hit the market, it is high time for a better strategic and time effective methodology in drug discovery process. InhA is a regulatory enzyme that catalyzes the final rate determining steps in mycolic acid synthetic pathway, which converts trans-2enoyl-ACP to acyl-ACP in an NAD-dependent reaction. Thus, it is one of the primary targets for most of the anti-tuberculosis drugs such as Isoniazid, Triclosan and diazoborines. Several approaches like computational simulations, de novo design and side activity optimization has been selectively deployed for developing inhibitors of InhA showing good potency. The known fact that the InhA protein has been well characterized and the possible chances of curtailing TB through its inhibition have increased its demand in the emerging mainstream drug discovery programmes. Following the rational mentioned above, the in silico based study was performed on InhA protein. On the base of INH mode of act, it has been anticipated that direct inhibitors of the enoylACP-reductase of Mycobacterium tuberculosis can explain anti-tubercular profile of Isoniazid. This also helps to overcome most of the issues associated with the drug like, drug resistance and toxicological effects. But very few molecules have attained clinical development. More modifications need to be done in enhancing the in vivo properties of the molecules, mostly the properties affecting ADME and also parameters which manipulate their potency for development of more efficient InhA inhibitors. Most of these drugs are unsuitable for human consumption because of poor solubility and toxicity. ${ }^{42}$ There are other drugs such as tolcapone and entacapone can directly inhibit InhAand these drugs are currently in clinical use, but they are under strict regulations in the United States because of hepatotoxicity. ${ }^{43}$ In addition, their potential utility to treat TB is still under half way to find out the ADMET/TOX properties. ${ }^{44}$ New class of direct InhA inhibitors comprising of alkyl diphenyl ethers of triclosan derivatives have been found to possess activity against drug-resistant strains of TB. Recently, the arylamides, indole-piperazines, pyrazole-based inhibitors, and indole-based inhibitors have been identified as other classes of direct InhA inhibitors still waiting for pharmacological studies. ${ }^{44}$

In an effort to identify suitable drug candidates through computer aided drug discovery, 1200 ligand molecules were virtually docked against the active site of InhA. After the docking process we have identified five molecules as the possible drug candidates. The compound for screening was obtained from Meta-database, which contain calculated three-dimensional coordinates and sometimes information about biological activity of the ligand compounds. The software LIGPLOT that adds further up to the computational biology by schematically generating the protein-ligand interaction mediated by hydrogen bonds and hydrophobic interaction showing a clear picture of interactions needed to screen the targets. Coupled with GOLD, SILVER programme has been used for the post-docking analysis of ligands and serves as a browser for visualizing docking results from GOLD. The study identified five putative small molecules as inhibitors that bind well to the active site of the target molecule chosen for the study. By using different computational strategy we have predicted that 9, 10, 16-trihydroxy hexadecanoic acid and 4-(1-pyrrolidinyl) butyl 2- cyclopentylpentanoate 2-hydoxy-1, 2, 3 propanetricarboxylate will directly inhibit InhA. Our prediction was eventually established by DruLiTOtests. Thus 9, 10, 16-trihydroxy hexadecanoic acid and 4-(1-pyrrolidinyl) butyl 2- cyclopentylpentanoate 2-hydoxy-1, 2, 3 propanetricarboxylate are promising lead compounds against TB. The drug likeliness properties of the lead molecules identified from the present study strongly substantiate their anti-tuberculosis properties and hence can be considered as the best lead and therefore in vitro and in vivo validation of the lead molecules are inevitable.

\section{CONCLUSION}

In the present study, the target InhA protein docked against 1,200 molecules that were virtually screened against its active site by employing molecular docking. The computational screening with the help of different softwares has resulted in the identification of few small molecules, which docked well into the active site of the target. The overall drug-likeness was tested with DruLito and Lipinski's rule of five. Three hits out of five obtained from redocking satisfied Lipinski's rule of five. Hydrogen bonding analysis and its examination also projected well into the affinity pattern of target protein active site with lead molecules. These five hits predicted to "dock" well as inferred from the GOLD score into the active site of InhA, should be considered as remarkable molecules that are needed to be further 
tested in the laboratory. On the other side, even though current docking methods show great promise, the accurate discrimination of ligands based on binding affinity is an important challenge.

\section{ACKNOWLEDGEMENT}

We express our heartfelt thanks to Dr. Achuthsankar S.Nair, Hon. Director, Department of Computational Biology and Bioinformatics, Kariavattom for the lab facilities provided for the work.

\section{CONFLICTS OF INTEREST}

The author(s) declared no potential conflicts of interest with respect to the research, authorship, and/or publication of this article.

\section{ABBREVIATIONS USED}

3D: 3 dimensional; ADME-Tox: Absorption, distribution, metabolism, and excretion-toxicity; BCG: Bacillus Calmette-Guérin; CADD: Computer Aided Drug Discovery; GOLD: Genetic Optimization for Ligand Docking; InhA: Enoyl acyl carrier protein reductase; LTB1: Latent TB infection; MTB: Mycobacterium Tuberculosis; NADP: Nicotinamide adenine dinucleotide phosphate; PDB: Protein Data Bank; RCSB: Research Collaborator for Structural Bioinformatics; TB: Tuberculosis; XDR: Extensively drug resistant.

\section{REFERENCES}

1. Sepkowitz KA. How contagious is tuberculosis?. Clinical Infectious Diseases. 1996;23(5):954-62. http://dx.doi.org/10.1093/clinids/23.5.954; PMid:8922785.

2. Rothman SM. Living in the shadow of death: tuberculosis and the social experience of illness in American history. 1994

3. Kochi A. The global tuberculosis situation and the new control strategy of the World Health Organization. Bulletin of the World Health Organization. 2001;79(1):71-5. PMid:11271466 PMCid:PMC2566329.

4. Smith I. Mycobacterium tuberculosis pathogenesis and molecular determinants of virulence. Clinical Microbiology Reviews. 2003;16(3):463-96. http://dx.doi.org/10.1128/CMR.16.3.463-496.2003; PMid:12857778 PMCid: PMC164219.

5. Barry CE, Boshoff HI, Dartois V, Dick T, Ehrt S, Flynn J, et al. The spectrum of latent tuberculosis: rethinking the biology and intervention strategies. Nature Reviews Microbiology. 2009;7(12):845-55. http://dx.doi.org/10.1038/ nrmicro2236.

6. Cohn DL, O'Brien RJ, Geiter LJ, Gordin F, Hershfield E, Horsburgh C. Targeted tuberculin testing and treatment of latent tuberculosis infection. MMWR Morb Mortal Wkly Rep. 2000;49(6):1-54

7. Somasundaram S, Ram A, Sankaranarayanan L. Isoniazid and rifampicin as therapeutic regimen in the current era: a review. Journal of Tuberculosis Research. 2014;2014.

8. Iseman M, Madsen L. Drug-resistant tuberculosis. Clinics in Chest Medicine. 1989;10(3):341-53. http://dx.doi.org/10.1080/00325481.1989.11704357.

9. Organization WH. Multidrug and extensively drug-resistant TB. 2010.

10. Organization WH. Global tuberculosis control: WHO report 2010: World Health Organization; 2010.

11. Espinal MA. The global situation of MDR-TB. Tuberculosis. 2003;83(1):44-51. http://dx.doi.org/10.1016/S1472-9792(02)00058-6.
12. Robert JB, Bastiaan EW, Canet D, Freeman R, Haeberlen U, MacLean C, et al. NMR at Very High Field. Springer Berlin Heidelberg. 2012.

13. Colditz GA, Brewer TF, Berkey CS, Wilson ME, Burdick E, Fineberg HV, et al. Efficacy of BCG vaccine in the prevention of tuberculosis: metaanalysis of the published literature. Jama. 1994;271(9):698-702. http:// dx.doi.org/10.1001/jama.1994.03510330076038 http://dx.doi.org/10.1001/ jama.271.9.698; PMid:8309034.

14. Bannon M. BCG and tuberculosis. Archives of Disease in Childhood. 1999;80(1):80-3. http://dx.doi.org/10.1136/adc.80.1.80; PMid:10325767 PMCid:PMC1717792.

15. Kamerbeek J, Schouls L, Kolk A, Van Agterveld M, Van Soolingen D, Kuijper S, et al. Simultaneous detection and strain differentiation of Mycobacterium tuberculosis for diagnosis and epidemiology. Journal of Clinical Microbiology. 1997;35(4):907-14. PMid:9157152 PMCid:PMC229700.

16. Clarridge Jr, Shawar RM, Shinnick TM, Plikaytis BB. Large-scale use of polymerase chain reaction for detection of Mycobacterium tuberculosis in a routine mycobacteriology laboratory. Journal of Clinical Microbiology. 1993;31(8):2049-56.

17. Kapetanovic I. Computer-aided drug discovery and development (CADDD): in silico-chemico-biological approach. Chemico-biological Interactions. 2008;171(2):165-76. http://dx.doi.org/10.1016/j.cbi.2006.12.006 PMid:17229415 PMCid:PMC2253724.

18. Chen Y, Zhi D. Ligand-protein inverse docking and its potential use in the computer search of protein targets of a small molecule. Proteins: Structure, Function, and Bioinformatics. 2001;43(2):217-26. http://dx.doi. org/10.1002/1097-0134(20010501)43:2<217::AID .

19. McMurry LM, McDermott PF, Levy SB. Genetic evidence that InhA of Mycobacterium smegmatis is a target for triclosan. Antimicrobial Agents and Chemotherapy. 1999;43(3):711-3. PMid:10049298 PMCid:PMC89191.

20. Laskowski RA, MacArthur MW, Moss DS, Thornton JM. PROCHECK: a program to check the stereochemical quality of protein structures. Journal of Applied Crystallography. 1993;26(2):283-91. http://dx.doi.org/10.1107/ S0021889892009944.

21. Grotthuss Mv, Koczyk G, Pas J, Wyrwicz LS, Rychlewski L. Ligand. info small-molecule meta-database. Combinatorial Chemistry \& High Throughput Screening. 2004;7(8):757-61. http://dx.doi.org/10.2174/1386207043328265.

22. GuexN, Peitsch MC. SWISS-MODEL and the Swiss-Pdb Viewer: an environment for comparative protein modeling. Electrophoresis. 1997;18(15):2714-23. http:// dx.doi.org/10.1002/elps.1150181505; PMid:9504803.

23. Jones G, Willett P, Glen RC, Leach AR, Taylor R. Development and validation of a genetic algorithm for flexible docking. Journal of Molecular Biology. 1997;267(3):727-48. http://dx.doi.org/10.1006/jmbi.1996.0897PMid:9126849

24. Wallace AC, Laskowski RA, Thornton JM. LIGPLOT: a program to generate schematic diagrams of protein-ligand interactions. Protein Engineering. 1995;8(2):127-34. http://dx.doi.org/10.1093/protein/8.2.127 PMid:7630882

25. Parker KC. Scoring methods in MALDI peptide mass fingerprinting: ChemScore, and the ChemApplex program. Journal of the American Society for Mass Spectrometry. 2002;13(1):22-39. http://dx.doi.org/10.1016/S10440305(01)00320-8

26. Laskowski RA. PDBsum: summaries and analyses of PDB structures. Nucleic Acids Research. 2001;29(1):221-2. http://dx.doi.org/10.1093/nar/29.1.221; PMid:11125097 PMCid:PMC29784

27. William MH, LiW, Uludag M, Squizzato S, Park YM, Buso N, et al. Analysis tool web services from the EMBL-EBI. NucleicAcids Research. 2013;41(W1):W597-W600. http://dx.doi.org/10.1093/nar/gkt376; PMid:23671338 PMCid:PMC3692137.

28. Bhal SK, Kassam K, Peirson IG, Pearl GM. The Rule of Five revisited: applying $\log D$ in place of $\log P$ in drug-likeness filters. Molecular Pharmaceutics. 2007;4(4):556-60. http://dx.doi.org/10.1021/mp0700209 ; PMid:17530776.

29. Oprea TI. Property distribution of drug-related chemical databases*. Journal of Computer-aided Molecular Design. 2000;14(3):251-64. http://dx.doi. org/10.1023/A:1008130001697; PMid:10756480.

30. Ghose AK, Viswanadhan VN, Wendoloski JJ. A knowledge-based approach in designing combinatorial or medicinal chemistry libraries for drug discovery. 1. A qualitative and quantitative characterization of known drug databases. Journal of combinatorial chemistry. 1999;1(1):55-68. http://dx.doi. org/10.1021/cc9800071 PMid:10746014.

31. Bickerton GR, Paolini GV, Besnard J, Muresan S, Hopkins AL. Quantifying the chemical beauty of drugs. Nature Chemistry. 2012;4(2):90-8. http:// dx.doi.org/10.1038/nchem.1243 PMid:22270643 PMCid:PMC3524573.

32. Vilchèze $C$, Morbidoni HR, Weisbrod TR, Iwamoto H, Kuo M, Sacchettini JC, et al. Inactivation of the inhA-encoded fatty acid synthase II (FASII) enoylacyl carrier protein reductase induces accumulation of the FASI end products and cell lysis of Mycobacterium smegmatis. Journal of Bacteriology. 
2000;182(14):4059-67. http://dx.doi.org/10.1128/JB.182.14.4059-4067.2000; PMid:10869086 PMCid:PMC94593.

33. Luckner SR, Liu N, am Ende CW, Tonge PJ, Kisker C. A slow, tight binding inhibitor of InhA, the enoyl-acyl carrier protein reductase from Mycobacterium tuberculosis. Journal of Biological Chemistry. 2010;285(19):14330-7. http:// dx.doi.org/10.1074/jbc.M109.090373; PMid:20200152 PMCid:PMC2863195.

34. Rozwarski DA, Vilchèze $C$, Sugantino $M$, Bittman $R$, Sacchettini JC Crystal structure of the Mycobacterium tuberculosis enoyl-ACP reductase, InhA, in complex with NAD+ and a C16 fatty acyl substrate. Journal of Biological Chemistry. 1999;274(22):15582-9. http://dx.doi.org/10.1074/ jbc.274.22.15582 ; PMid:10336454

35. Quemard A, Dessen A, Sugantino M, Jacobs WR, Sacchettini JC, Blanchard JS. Binding of catalase-peroxidase-activated isoniazid to wild-type and mutant Mycobacterium tuberculosis enoyl-ACP reductases. Journal of the American Chemical Society. 1996;118(6):1561-2. http://dx.doi.org/10.1021/ ja950998b.

36. Argyrou A, Vetting MW, Blanchard JS. New insight into the mechanism of action of and resistance to isoniazid: interaction of Mycobacterium tuberculosis enoyl-ACP reductase with INH-NADP. Journal of the American Chemical Society. 2007;129(31):9582-3. http://dx.doi.org/10.1021/ja073160k; PMid:17636923 PMCid:PMC2525798.

37. Quemard A, Sacchettini JC, Dessen A, Vilcheze C, Bittman R, Jacobs Jr WR, et al. Enzymic characterization of the target for isoniazid in Mycobacterium tuberculosis. Biochemistry. 1995;34(26):8235-41. http://dx.doi.org/10.1021/ bi00026a004 ; PMid:7599116.
38. Thompson MA. ArgusLab 4.0. 1. Planaria Software LLC, Seattle, WA. 2004.

39. Pawson AJ, Sharman JL, Benson HE, Faccenda E, Alexander SP, Buneman OP, et al. The IUPHAR/BPS Guide to PHARMACOLOGY: an expertdriven knowledgebase of drug targets and their ligands. Nucleic Acids Research. 2014;42(D1):D1098-D106. http://dx.doi.org/10.1093/nar/gkt1143; PMid:24234439 PMCid:PMC3965070.

40. Gaulton A, Bellis LJ, Bento AP, Chambers J, Davies M, Hersey A, et al. ChEMBL: a large-scale bioactivity database for drug discovery. Nucleic Acids Research. 2012;40(D1):D1100-D7. http://dx.doi.org/10.1093/nar/gkr777; PMid:21948594 PMCid:PMC3245175.

41. Kuo MR, Morbidoni HR, Alland D, Sneddon SF, Gourlie BB, Staveski MM, et al. Targeting tuberculosis and malaria through inhibition of Enoyl reductase: compound activity and structural data. The Journal of biological chemistry. 2003;278(23):20851-9. Epub 2003/02/28. http://dx.doi.org/10.1074/jbc. M211968200 ; PMid:12606558

42. Borges N. Tolcapone-related liver dysfunction: implications for use in Parkinson's disease therapy. Drug safety. 2003;26(11):743-7. Epub 2003/08/12. http://dx.doi.org/10.2165/00002018-200326110-00001; PMid:12908845.

43. Kinnings SL, Liu N, Buchmeier N, Tonge PJ, Xie L, Bourne PE. Drug discovery using chemical systems biology: repositioning the safe medicine Comtan to treat multi-drug and extensively drug resistant tuberculosis. PLoS Computational Biology. 2009;5(7):e1000423. Epub 2009/07/07. http://dx.doi. org/10.1371/journal.pcbi.1000423 ; PMid:19578428 PMCid:PMC2699117.

\section{SUMMARY}

- Tuberculosis (TB) is one of the Neglected tropical diseases (NTDs), caused by the bacterium Mycobacterium tuberculosis (MTB). Prevention of TB involves screening those at high risk, early detection and treatment of cases, vaccination and by means of several antibiotics. The administration of antibiotics such as Isoniazid and Rifampicin fails due to the multi-drug resistant capability of Mycobacterium. Traditional methods require time and huge investment. Therefore, it is essential to provide an alternative strategy to treat tuberculosis disease. The Computer aided drug discovery has been developed as a fast and reliable technique to identify potential drug candidates through docking studies. The purpose of this study was to perform docking InhA target protein, one of the main protein for mycolic acid production and cell wall synthesis of MTB. A number of 1,200 small molecules virtually screened against InhA active site using GOLD (Genetic Optimization for Ligand Docking) software that uses Genetic Algorithm (GA). The total cell wall synthesis of mycobacterium can be ended through inhibition of InhA. In this study, five putative dug candidates were identified after the initial screening. The predictions performed for many biological effects such as $\mathrm{H}$-bonding investigation, Lipinski's rule evaluation, and drug likeliness tests of this drug candidates. The results showed remarkable capability as potential drug candidates and safer anti-Mycobacterial drug agents that are needed to be further tested in the laboratory.

\section{About Authors}

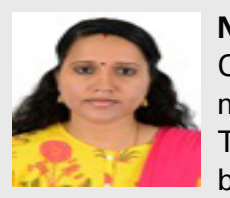

Nisha.T.Nair, M.Sc: Is a MPhil student at Department of Biotechnology, Malanakara Catholic College, Trivandrum, kerala, India. She is currently working with the project on the development of molecular marker for dasheen mosaic in Amorphophallus using bioinformatics tools at ICAR-Central Tuber Crops Research Institute, Trivandrum. The project involves the development of different bioinformatics pipeline for developing SNPs. She did her Masters in Bioinformatics at National college of Applied Science, Trivandrum, kerala, India.

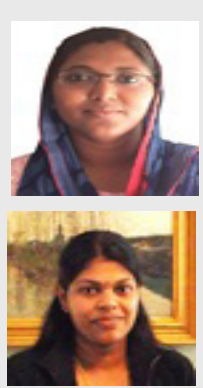
Mrs. Shefin.B Shefin.B: Is a Junior Research Fellow doing Ph.D at Biotechnology and Bioinfomatics Division, Jawaharlal Nehru Tropical Botanic Garden and Research Institute, Puthenthope. Her Ph.D work focuses on validating the anti-tuberculosis potential of nutraceutical plants reported in traditional medicine. She had previously worked with of Open Source Drug Discovery, CSIR, New Delhi in an interactome driven drug target identification in Mycobacterium tuberculosis.

Mrs. Bindu A. Sunilkumar, M.Sc, M.Phil (Corresponding author) is a research student at the department of Applied Nutrition and Food Chemistry, Lund University, Sweden. Bindu A. Sunilkumar studies the inherent resources of the oat genome. The project aims to exploit the inherent resources of the oat genome to develop high quality oats especially designed from the "end users" specifications 